\title{
POBREZA E EXCLUSÃO SOCIAL NA VIOLAÇÃO DE DIREITOS DAS CRIANÇAS E ADOLESCENTES EM SITUAÇÃO DE RUA
}

\author{
Ranulfo Cavalari Neto \\ SÔNIA Maria Dantas Berger \\ Joana Mansur de Souza \\ Paula Kawamme Latgé \\ MÔnica Tereza Christa Machado \\ Marlene Merino Alvarez \\ Universidade Federal Fluminense (UFF), Niterói, Rio de Janeiro, Brasil
}

Resumo: As crianças e adolescentes em situação de rua, sujeitos historicamente excluídos, refugo humano de seres sobrantes, os sem lugar que não cabem na foto e nem na escola, passam ao largo das políticas educacionais. A partir de breve abordagem sócio histórica sobre a produção da infância excluída no Brasil, e da realidade vivenciada no projeto de extensão de uma universidade pública do estado do Rio de Janeiro, o propósito deste artigo foi discutir e compreender como a educação formal, ou a ausência dela, marca a vida dessas crianças e adolescentes, tomando como referência a história de vida de uma jovem negra cuja primeira experiência de rompimento social e institucional foi com a escola. Afirma-se a urgência de relações sociais menos excludentes e desiguais para se viabilizar 0 acesso e permanência dessa população na escola e seu direito à educação.

Palavras-chave: Pessoas em situação de rua. Pobreza. Exclusão social. Educação.

INTRODUÇÃO

Que excelência é essa que não se comove com o extermínio de meninas e meninos nos grandes centros urbanos brasileiros; que "proíbe" que 8 milhões de crianças populares se escolarizem, que "expulsa" das escolas grande parte das que conseguem entrar.

Paulo Freire

A exclusão decorrente das desigualdades sociais e da pobreza pode ser analisada por diversos ângulos, contudo nenhum deles poderá se dar sem que sejam discutidas as políticas públicas implementadas pelo Estado. Nascimento e Scheinvar (2005), na linha do que é discutido por Robert Castel (1996, p.56), sinalizam que " a noção de exclusão social vem sendo utilizada de maneira muito inflacionada e heterogênea (...) cobrindo realida 
des por demais díspares". No campo das políticas educacionais e no contexto neoliberal vigente:

(...) a relação Estado e políticas públicas pressupõe que o Estado orienta-se em função de uma racionalidade: homogeneização, inclusive através da educação; como modos para homogeneizar utiliza o trabalho, o consumo ou a competência tecnológica; e é em função destes aspectos que se produz a exclusão social (BONETI, 1997, p. 198)

Nesse cenário, as crianças e adolescentes em situação de rua são atores sociais que sobram diante de tal política educacional. Na perspectiva de Bauman (2005, p. 12), são excluídos os que se encaixam na categoria de refugo humano, seres sobrantes, "excessivos" e "redundantes", produto indissociável do processo de modernização, nas palavras do autor, "um inescapável efeito colateral da construção da ordem e de progresso econômico". Sendo assim, a educação enquanto controle de massas não capta essas crianças. Por outro lado, poderia assumir um caráter de instrumento de libertação, mas, também nesse caso, ainda não as alcança e nem as enxerga, como indignado se revela Paulo Freire em suas reflexões so bre classes sociais e o capitalismo.

A partir de uma abordagem sócio histórica, sob a perspectiva da necessária intersetorialidade entre as políticas públicas de educação, saúde e assistência social e da interseccionalidade, principalmente entre classe e raça/cor, o objetivo deste artigo foi compreender como a educação formal (ou a ausência dela) marca a vida das crianças e adolescentes em situação de rua, observando e analisando a realidade da pobreza, exclusão social e produção de infâncias desiguais, a partir da experiência de um projeto de extensão de uma universidade pública localizada no estado do Rio de Janeiro.

\section{MetOdologia}

0 presente artigo parte do reconhecimento da infância como uma construção sócio histórica e tem como proposta metodológica identificar elementos do processo pedagógico-doutrinário presentes na história do Brasil, para verificar os resquícios, restos e totalidades presentes na atualidade, os quais são reconhecidos e trabalhados por meio do encontro da extensão universitária com serviços das redes de saúde e sócio assistencial.

O projeto de extensão universitária do qual emerge este artigo é produto do campo da Saúde Coletiva, onde a proposta visa produzir outros modos de ver, ouvir, sentir e interagir com as crianças e adolescentes em situação de vulnerabilidade, a partir da intersetorialidade, para amparo de demandas complexamente constituídas, não elucidadas com ações simplificadas e imediatistas. Além disso, o projeto tem como objetivo também sensibilizar a sociedade em relação a esse grupo social, ampliar o olhar dos alunos de graduação e pós-graduação, professores, técnicos e profissionais envolvidos sobre as desigualdades, a violência, a pobreza e a integralidade no cuidado em saúde e produzir acesso aos serviços (saúde, assistência social, educação e outros). 
NETO, R.C.; BERGER, W. M. D.; SOUZA, J. M. de; LATGÉ, P. K.; MACHADO, M. C. T.; ALVAREZ, M. M.

A temática aprofundada é fruto das observações e discussões realizadas por professores, profissionais e alunos integrantes da ação interinstitucional e intersetorial Ocupa Praça, inserida no projeto de extensão do Instituto de Saúde Coletiva da Universidade Federal Fluminense (ISC/UFF), “Crianças e adolescentes em situação de rua e/ou acolhimento institucional: construindo estratégias de territorialização afetiva", o qual está registrado no Sistema de Informações e Gestão de Projetos do MEC (SIGPROJ) sob o número 291786.1598.198453.28012018.

A ação Ocupa Praça visa ampliar os trabalhos no território, fortalecendo vínculos e articulando ações de diferentes serviços e políticas, tais como: centro de atenção psicossocial infantojuvenil (CAPSi), consultório na rua, unidade de acolhimento infantojuvenil, centro de convivência e cultura da saúde mental, programa de erradicação do trabalho infantil, serviços de proteção social especial de alta complexidade, políticas de saúde, assistência social e de promoção dos direitos das crianças e adolescentes, além do Fórum e do Conselho Municipal de Promoção dos Direitos de Crianças e Adolescentes e do ISC/UFF. Desta forma, envolvendo toda a rede de cuidado, promove atividades de cunho recreativo e educativo, realizadas de maneira lúdica por convidados e/ou professores, técnicos e alunos de graduação e pós-graduação da UFF e profissionais dos serviços supracitados. As atividades são registradas em livro ata, fotos e vídeos. São garantidos encontros semanais com as equipes envolvidas, para reflexão técnicocientífica sobre o trabalho coletivo e grupos de estudo mensais para leitura e discussão de textos nos campos da Educação e Saúde, alinhados às contribuições da obra Freireana e à bandeira de luta da integralidade em saúde no Sistema Único de Saúde (MATTOS, 2006).

A equipe interinstitucional se reúne de dois em dois meses para avaliar e programar as atividades mensais do Projeto. 0 encontro de avaliação ocorre no CAPSi e conta com a participação dos envolvidos no evento e representantes do público alvo.

No presente artigo, foi abordada a discussão relativa à educação formal das crianças em situação de vulnerabilidade, emergente rotineiramente nos grupos de estudo e avaliações do projeto.

\section{INFÂNCIA EPOLITICASPÚBLICAS: ENTRE O ASSISTENCIALISMO AOSABANDONADOSEA EXCLUSÃO DOS MENORES PERIGOSOS}

Sem a pretensão de se traçar um percurso completo, desde que os padres jesuítas aqui chegaram para iniciar uma intervenção pedagógico-doutrinária das crianças indígenas, o que se configurou mais como uma catequese do que um processo de escolarização, faz-se necessário demarcar algumas concepções e práticas que, desde então, foram dirigidas às crianças, adolescentes e famílias em situação de vulnerabilidade social, ou seja, que fizeram e continuam a fazer parte da infância excluída no Brasil.

A infância, enquanto uma construção sócio histórica e dentro da sociedade brasileira no período colonial, que priorizava a disciplina e a moral, teve como dispositivo central a educação religiosa. Porém, desde o começo, seguindo princípios da sociedade de classes, o ensino teve propostas e práticas diferenciadas: enquanto as crianças das famílias mais abastadas eram educadas ao lado dos pais e para ocuparam funções de 
mando, as das famílias mais pobres, muitas delas negras e filhas de escravos, eram enviadas a instituições totalitárias nas quais eram preparadas para servir (NASCIMENTO; SCHEINVAR, 2005).

Os primeiros internatos de menores, locais destinados para o recolhimento provisório ou permanente de crianças e adolescentes consideradas moralmente abandonadas e "desvalidas", ou seja, sem valor - órfãos, carentes e delinquentes -, eram instituições construídas e administradas a partir da caridade pública, sem custo para o governo, já caracterizando a desassistência e ausência de proteção do poder público. No caso da Roda dos Expostos, alguns senhores de escravos ainda lucravam com tal sistema: "abandonavam o bebê cativo na roda, alugavam sua mãe como ama de leite e, mais tarde, mandavam buscar o menino já crescido, que lhes pertencia, para trabalhar" (LEITE, 2009, p.15).

No Rio de J aneiro Imperial, por volta de 1850, as crianças pertencentes à chamada "infância abandonada", eram alvos de preocupação na medida em que precisavam ser produtivas, pois o que importava era a sua formação enquanto cidadãos disciplinados e úteis à pátria. Nesse sentido, representantes da elite, no caso os fazendeiros, passam a oferecer o ensino primário para as crianças, aliado ao conhecimento agrícola, de modo a proporcionar mão de obra para o trabalho nas fazendas, em decorrência da "falta de braços" e de "capitais" nas lavouras. Dessa forma, as crianças pobres, abandonadas, órfãs, vagabundas e ingênuas (categorias pertencentes à "infância abandonada") seriam educadas pelos senhores fazendeiros, em instituições asilares de ensino agrícola (SCHUELER, 1999; FRANCISCO, 2013). A preocupação da Corte e dos senhores fazendeiros era garantir a segurança de quem já usufruía da propriedade e do bem-estar da sociedade instituída.

Segundo Ligia Costa Leite (2009), uma inovação se deu quando foi inaugurada a primeira instituição a ser totalmente administrada pelo Estado, a Escola XV de Novembro, já na República Velha, a qual tornou-se modelo na educação e assistência social de crianças que se encontravam nas ruas. Embora orientada por uma proposta pedagógica inovadora para a época, a mesma acabou não conseguindo romper com o modelo tradicional de internato, sendo que, nos muitos anos de funcionamento, esteve vinculada aos setores da Assistência Social e da Justiça, mas nunca ao da Educação, o que reforça a visão hegemônica de que os mesmos deveriam ser assistidos, enquanto abandonados, ou punidos, enquanto jovens transgressores.

Com o tempo, o número de instituições que abrigavam os filhos da pobreza passou a não ser suficiente para a quantidade de crianças e adolescentes, que acabavam nas ruas. Já no século XIX, esse grupo social era considerado como um perigo para a sociedade e alvo de mecanismos de exclusão e repressão, que tinham como propósito evitar a desordem e a perturbação social (LEITE, 2009). Desse modo, a criminalização da pobreza é um processo construído, social e politicamente, que predomina até hoje.

Assim, meninos e meninas pobres, frutos de um projeto político excludente e injusto, foram, durante muito tempo, trancafiados e isolados para serem moldados em nome de uma ressocialização planejada para eles. A sociedade tenta reconduzir aquilo que ela produziu como um perigo ameaçador. 


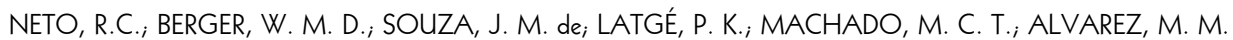

\section{DE "MENORES" A SUJEITOS DE DIREITOS: O QUE MUDOU?}

Para Molina (2012), ao se discutir política pública, é necessário considerar quatro conceitos fundamentais: direitos, Estado, movimentos sociais e democracia. Na busca por políticas alternativas que integrassem as crianças ao meio social, somente na década de 1980, e na articulação desses quatro conceitos, foi possível se avançar no fortalecimento dos questionamentos direcionados à lógica manicomial e excludente de institucionalização de crianças e adolescentes, vigente no Brasil (RIZZINI; RIZZINI, 2004). Vale ressaltar o contexto de abertura política do Brasil, no qual, a partir de debates, manifestações, articulações e movimentos sociais, incluindo os de meninos e meninas de rua, foi possível construir mudanças e avançar no campo das políticas sociais e legislações.

No âmbito dos direitos de crianças e adolescentes, destaca-se a promulgação do Estatuto da Criança e do Adolescente (ECA) em 1990, que determina a proteção integral e especial, sem discriminação, para todas as crianças e adolescentes, como prioridade absoluta do Estado e da sociedade. No entanto, apesar dos avanços, ainda há muitos desafios na estruturação de políticas públicas que garantam os direitos que são assegurados pela legislação, uma vez que é possível perceber que muitas delas, principalmente aquelas em situação de vulnerabilidade associada à pobreza e ao racismo, ainda se encontram com pouco ou nenhum acesso à educação, lazer, saúde, alimentação, dentre outros direitos.

O Estado, apesar de ser responsável pela criação e execução de políticas voltadas à promoção, proteção e garantia de direitos, continua exercendo práticas que produzem e reproduzem a exclusão, violando seus direitos básicos, à margem das políticas públicas. Nesse contexto, é importante destacar que o Ministério da Saúde (2001, p. 15) define violência contra crianças e adolescentes como "quaisquer atos ou omissões dos pais, parentes, responsáveis, instituições e, em última instância, da sociedade em geral, que redundam em dano físico, emocional, sexual e moral às vítimas". Assim, tais violaçóes, ao serem negligenciadas pelo Estado e pela sociedade em geral, são violências praticadas inclusive pela instituição escolar contra as clássicas 'crianças-alunas-problema' que, na verdade, denunciam os limites do modelo educacional vigente, e, ao não serem ouvidas, pouco a pouco são e/ou sentem-se excluídas, encontrando na rua uma saída.

\section{A EXTENSÃO UNIVERSITÁRIA NUM CONTEXTOS DE VIOLÊNCIA, POBREZA E DESASSISTÊNCIA}

Segundo Paulo Freire, a extensão universitária é uma prática a uma cultura, necessariamente, dialogal, educativa e comunicacional. Ainda sobre extensão, 0 educador aponta que: “[...] sua ação (...) se dá no domínio do humano e não do natural, o que equivale dizer que a extensão de seus conhecimentos e de suas técnicas se faz aos homens para que possam transformar melhor o mundo em que estão (...)" (FREIRE, 1983, p.11).

Além disso, criticava a extensão universitária como uma prática unilateral e invasiva às culturas populares, uma vez que, desse modo, não considera a dimensão humana e a cultura local. Segundo De Paula (2013), é tarefa da extensão construir a relação de compartilhamento entre o conhecimento científico e tecnológico produzido na universidade e os conhecimentos de que são titulares as comunidades tradicionais. 
Assim, tem-se a promoção da interação dialógica para a diversidade como condição para a autodeterminação, para a liberdade, para a emancipação.

Uma das situações vivenciadas pela equipe do projeto de extensão é exemplar no que tange à trajetória escolar, à discriminação e exclusão social sofridas, e à desassistência vivenciada por uma adolescente negra em situação de rua. A cena a seguir, aconteceu em um serviço de saúde mental voltado para o público infantojuvenil de um município do estado do Rio de Janeiro.

O serviço de saúde mental realizou uma confraternização de Festa Junina, reunindo seus usuários, suas famílias, a população infantojuvenil em situação de rua, trabalhadores da rede de saúde do município e usuários de outros dispositivos da saúde mental. Era um dia chuvoso, e, com isso, não foi possível realizar a festa na praça, conforme planejado, anteriormente. Dessa forma, o serviço de saúde mental tinha pouca disponibilidade física para acomodar a todos. Os adolescentes em situação de rua, que são atendidos no serviço, eram poucos naquele dia e estavam na sala. Em função da chuva, outras crianças usuárias do serviço de saúde mental, que estavam jogando bola na área externa, se dirigiram para a mesma sala e prosseguiram brincando com a bola. Foram alertados, mais de uma vez, pelos adolescentes em situação de rua, que parassem com a brincadeira de bola dentro da sala, pois, segundo as regras, não era permitido. Entretanto, as crianças continuaram. Em determinado momento, a bola acertou um dos adolescentes, que reclamou de forma áspera e alta com a criança que chegou ao serviço de saúde mental acompanhado da mãe. A mãe da criança, vendo o ocorrido, chama a atenção do adolescente, aos gritos, por ele ter falado de forma grosseira com seu filho. Nesse momento, outra adolescente intervém, defendendo o outro, a quem chama de "irmão". Tem-se início uma grande confusão, em que a adolescente e a mãe da criança trocam muitos gritos, ofensas e ameaças. A situação foi contornada, inicialmente, pela equipe do serviço de saúde mental, promovendo o afastamento das duas. Posteriormente, a adolescente se aproxima de um dos membros da equipe de extensão, do lado de fora da sala, com os olhos marejados e a voz embargada, pedindo desculpas, afirmando saber que estava errada, por ter gritado e ameaçando a moça. Mas, que, "doeu em seu coração" ouvir que ela não tinha o direito de chamar a atenção da criança, por "não ter mãe" e ser "largada e de rua". Imediatamente, insiste: "eu não sou de rua, eu não nasci na rua e eu tenho mãe", afirma que estava na situação de rua por questões dela e de dificuldades de sua mãe, mas que, ainda assim, não dava o direito à moça de falar com ela daquela forma.

A situação, presenciada acima, traz à tona conceitos importantes para pensar o processo possível para chegar até à vivência na rua. Castel (1994) trata da dinâmica do processo de marginalização e destaca duas zonas importantes: de vulnerabilidade e de "desfiliação". O autor trata a marginalização enquanto resultado de uma sociedade que opera com a lógica da exclusão, que produz efeitos dessocializantes. As situações marg inais, tanto para as crianças e adolescentes quanto para suas famílias, são resultados de um duplo processo de desligamento, sendo ele do trabalho e em relação à inserção relacional. A zona de vulnerabilidade tem início com o trabalho precário (ambulantes, trabalhadores do campo, por exemplo, ou seja, todo trabalho marcado pela precariedade de seu salário e a instabilidade), junto com a fragilidade dos apoios relacionais (apoio so 
cial). Por outro lado, a zona de "desfiliação" está vinculada à ausência de trabalho e isolamento relacional. Deve ser lembrado que tais zonas não são estáticas e nem são dadas em definitivo, segundo o autor, na medida em que suas fronteiras são móveis.

As crianças e adolescentes são as maiores vítimas desse sistema da violência estrutural. A exposição à desfiliação é visível e progressiva, por meio de tamanha desigualdade racial e social. Na zona de vulnerabilidade, provavelmente, as crianças e jovens são colocadas em uma situação onde elas precisam trabalhar. Nesse cenário, para trabalhar, terão que abdicar dos estudos, esgarçando ou rompendo com o vínculo escolar. Assim, diminuindo as possibilidades de obter recursos para melhorar suas condições de vida. É desse modo que a roda gira e se propaga (ARAUJ O; SILVA; OLIVEIRA, 2013).

$\mathrm{Na}$ rotina da ação extensionista, o tema da educação era algo que sempre gerava muitas dúvidas na equipe, visto que essa demanda deixava interrogações sobre a história de vida daquela população, marcada predominantemente pela cor de pele negra, que antes de estarem na rua experienciaram rompimentos sociais e institucionais, sendo um deles com a escola. A mesma adolescente que aparece na cena anterior, reivindicando que sua história de vida tem importância e que nenhuma criança "nasce" na rua, narrou um pouco mais sobre sua história na interface com a educação formal quando ainda era criança com seus 12 anos. Próximo de seus 18 anos, a adolescente não consegue ler, nem escrever. Ela conta que na sua infância, em uma comunidade marcada pela violência, sua mãe trabalhava e conseguia pagar uma pessoa que a ajudava a estudar em casa, ou seja, aulas de reforço. Porém, quando sua mãe adoece e não consegue mais trabalhar, a menina se vê sem possibilidades de ter seu reforço escolar, nem de continuar frequentando a escola. Ela conta que, devido à gravidade da condição de saúde de sua mãe, foi necessário parar de frequentar a escola para ajudar nos cuidados com a mãe, além disso, a cozinhar, lavar e cuidar das tarefas domésticas.

O que mais a levaria a sair de casa? Crianças abandonadas, filhos de pais que durante muitos anos estiveram alijados do mercado de trabalho ou nunca nele estiveram inseridos, emolduram hoje o quadro do lúmpen moderno. Não são simplesmente "crianças abandonadas" pelas famílias; são, na verdade, produto do próprio processo de exclusão social, condição já herdada dos pais como estigma de gerações. Ao que aponta Kowarick (1983), um fenômeno de espoliação urbana, de combinação da extensa exploração da força de trabalho com as precárias cond ições de vida.

Outras histórias foram contadas pelas crianças e adolescentes e todas elas têm em comum a vulnerabilidade social, as desigualdades e a pobreza como elementos centrais na condição de vida que possuíam. Nesse ponto, fica explícito que as políticas sociais podem até proporcionar o acesso dessas crianças à escola, porém não conseguem que permaneçam nela, revelando uma falha de garantia de direitos por parte do Estado. É preciso superar a culpa pelo fracasso escolar colocada nas crianças, adolescentes e suas famílias, e propor soluções para a total descrença em relação à escola, que os discrimina e culpabiliza por todas as arestas impostas por esse sistema opressor no qual vivemos.

Os episódios da vida de uma criança, coibida de um lar e levada pelas contingências a viver nas ruas, são acompanhados com extrema crueldade pela sociedade, ao fechar os olhos e não reconhecer um de seus próprios produtos como acidente de percurso. É mais fácil tomar atitudes que vão desde a postura de indiferença, até nuances variadas de assistencialismo como instância remediadora, quando não ao ex 
termínio sumário. Não se elabora, de fato, um projeto amplo de discussão das causas geradoras, seguido de definição de linhas de ação para combate verdadeiro a essas causas. Parece haver um fosso entre o determinismo social e a superação das causas geradoras.

Além de coibido do acesso à moradia, à escola, ao alimento e de uma condição de vida adequada, é culpado pela pobreza. Crianças de adolescentes que vivem em situação de rua acabam sendo considerados como um problema quando, na realidade, assim vivem porque são destituídos de cidadania. Sob duplo estigma, enfrentam destino mordaz: 0 abandono moral.

As desigualdades segundo sua raça/cor também têm sido documentadas nas pesquisas em saúde, com os segmentos socialmente menos favorecidos, incluindo pretos, pardos e indígenas, apresentando níveis mais elevados de adoecimento e morte.

A pobreza na infância tem cor, atingindo mais da metade das crianças negras. Segundo o Censo 2010, mais de $60 \%$ das crianças e adolescentes entre 4 e 17 anos de idade que estão fora da escola, são negras (IBGE, 2010).

O racismo no Brasil produz e reproduz violências sentidas na pele de $53,6 \%$ dos brasileiros, declarados pretos e pardos (IBGE, 2014). A abolição da escravatura não significou a conquista da cidadania para os negros, ou o alcance da igualdade racial, tampouco garantiu a inserção no mercado de trabalho. A partir das pesquisas (BRASIL, 2017; CASTRO; OLIVEIRA, 2018) que tratam sobre os desdobramentos desse tema, é possível analisar que somente quando o Estado assumir que a violência letal está endereçada, principalmente à população negra, e que há uma relação com as desigualdades socioeconômicas, se iniciaria um processo de desenvolvimento de políticas públicas direcionadas e ações afirmativas visando à diminuição dessas iniquidades.

Assim sendo, surgem os seguintes questionamentos: como superar a concepção minimalista da pobreza, da desigualdade e da educação em relação às crianças e adolescentes em situação de rua? Primeiramente, é importante destacar que a resposta a essa pergunta, não se dará tão facilmente assim, pois existe uma complexidade históricosocial que consiste em uma repetição geracional de continuação da exclusão e negação de direitos, uma herança maldita de processos de desigualdade que definem lugares sociais difíceis de serem ultrapassados. Tal complexidade precisa ser contemplada para o entendimento da história de crianças e adolescentes em situação de rua no Brasil, ou mais comumente conhecidos como "os menores".

\section{E A ESCOLA? SOLUÇÃO OU REPRODUÇÃO?}

A constituição de um campo específico de reflexão em torno da relação entre situação de pobreza e educação formal urge, pois, sem ele, como pensar uma pedagogia contra-hegemônica? Como desenvolver os elementos que deveriam incluir uma visão renovadora da pedagogia, no intuito de construiruma verdadeira pedagogia da inclusão? (YANOULLAS; ASSIS; FERREIRA, 2012, p.348) 
NETO, R.C.; BERGER, W. M. D.; SOUZA, J. M. de; LATGÉ, P. K.; MACHADO, M. C. T.; ALVAREZ, M. M.

O desafio colocado nas indagações acima pode ser constatado na pesquisa das autoras que, entre 69 publicações e produções acadêmicas revisadas, buscou levantar como vem sendo abordada a relação entre a educação formal e a situação de pobreza. A pesquisa identificou 13 diferentes tipos de relação, sendo que as duas mais frequentes foram as que, sob uma perspectiva positiva, colocam a educação formal como condição para o rompimento do círculo de pobreza e as que, com um olhar negativo, reconhecem a mesma como reprodutora da ordem social (YANNOULAS; ASSIS; FERREIRA, 2012, p. 339).

Com seus direitos básicos negados, como foi o caso da adolescente, destacado anteriormente, a educação, a alimentação e habitação são elementos que vão sendo destituídos e cada vez menos acessados. Essas crianças e adolescentes desenvolveram um comportamento "guerrilheiro" de sobrevivência, como escreve Lígia Costa Leite narrando a experiência da Escola Tia Ciata, destinada a alfabetização de crianças e jovens entre 12 e 20 anos que estavam em situação de rua no Rio de Janeiro nos anos 80 . A criatividade, nesse caso, está ligada à resistência em busca da preservação da vida, valor que só acaba com a morte. Esse modo de viver denuncia não só a ausência do Estado, mas sim de toda a sociedade, pautada na valorização do consumo exacerbado, na aquisição de bens e posses e na "coisificação" da vida, ou seja, a redução à condição de objeto de crianças e adolescentes, interditadas na sua dimensão do ser.

Esse comportamento guerrilheiro, irreverente e agressivo, reflexo do que sofrem nas ruas, torna-se o ponto de partida para qualquer trabalho pedagógico e de cuidado em saúde com elas e eles. No caso do projeto de extensão, existe uma aposta, por meio da territorialização afetiva, que busca transpor os estigmas existentes sobre a população em situação de rua, por meio da ocupação de espaços públicos e da luta política em espaços coletivos de reivindicação de direitos.

Muitas formas de exclusão social estão presentes nas cidades, e talvez seja possível conceber que o processo de organização das cidades é originalmente excludente, tendo em vista que historicamente tem por base a divisão do trabal ho, além de se realizar por meio de trocas, o que exige que se possua elementos de negociação, tais como força de trabalho (o próprio corpo), bens de consumo, entre outros. Nesse sentido, aos sem posse fica reservado o lugar de resto, o lugar dos desenquadrados, dos que não cabem na foto, na escola, no mundo, cada vez mais estigmatizados. Nesse meio, se confunde a pobreza e a vitimização com a delinquência e a transgressão das normas, mas é preciso deixar claro que a pobreza e as desigualdades de hoje são também fonte de injustiças e de problemas sociais no futuro (CAMPOS, 2014).

Um fato frequentemente reproduzido pelo setor de educação e outros setores da política pública, é o discurso da atribuição da exclusão social a fatores individuais, ou seja, pessoas que tiveram seus direitos sociais negados são reduzidas a responsáveis pelo seu processo de exclusão, em uma sociedade que converte padecedores em culpados.

No trabalho voltado às crianças e adolescentes em situação de rua, histórias de desamarração dos vínculos, rupturas de suas relações afetivas, se repetem: primeiro o alinhavo dos vínculos familiares se rompe, dando início à permanência no território de origem, a partir de certa cegueira/impossibilidade de serviços territorializados (Escola, Estratégia Saúde da Família - ESF, Centro de Referência da Assistência Social - CRAS). Assim, o afastamento gradual se concretiza, indo da casa para escola, da escola para casa; 
da casa para rua, da escola para rua; da rua para rua; sempre a caminho do "Reino do Tão Tão Distante", como na Fábula de Shrek.

Passo a passo os distanciamentos se agravam, e a produção do não lugar se consolida, já não mais a escola formal, a Atenção Básica em Saúde, o CRAS, o acolhimento institucional, pois agora entram na cena a internação socioeducativa, a internação compulsória e a morte, convocando-se os especialistas da exclusão. Por outro lado, como apontam Yannoulas, Assis e Ferreira (2012), detecta-se uma ausência de incorporação nas escolas e na educação formal de adolescentes em liberdade assistida, abrigados. Enfim, como (não) se articulam educação, assistência social e saúde!

É preciso e urgente afirmar que não se trata de construir saídas espetaculares, saberes especializados, e sim de produzir relações sociais menos excludentes e desiguais, de educação e cuidado ampliados dentro e fora de sala de aula. Pois, como diz o provérbio africano e que passou a ser um lema do projeto de extensão, "é preciso uma cidade inteira para cuidar de uma criança!".

\section{CONSIDERAÇÕES FINAIS}

As situações vivenciadas na esfera de uma ação extensionista e abordadas neste artigo, que trata da relação entre a educação formal e crianças e adolescentes em situação de rua, simbolizam apenas um sintoma do processo de exclusão social vivido pelos mais pobres desde o Brasil Colônia. Os atores sociais priorizados nas reflexões aqui colocadas meninos e meninas em situação de rua/vulnerabilidade - escapam da política educacional brasileira, e, da mesma forma, quando estão nas instituições escolares sofrem a reprodução da violência estrutural que está no cotidiano das grandes cidades. Tal complexidade histórico-social de crianças e adolescentes em situação de vulnerabilidade passa pela domesticação dos corpos - iniciativas de catequização dos povos originários , em seguida pelo racismo que produz e reproduz violências contra as crianças negras, logo depois pela organização excludente das cidades; e, por fim, na manutenção do ordenamento social vigente onde não há lugar para o rompimento do círculo de pobreza instaurado sobre os povos mais pobres e periféricos.

Nesse sentido, atualmente buscam-se iniciativas intersetoriais e interinstitucionais que invistam na superação das desigualdades vividas no Brasil. Aqui convocamos todas e todos os educadores (professores, diretores, conselheiros tutelares, assistentes sociais, profissionais de saúde e sociedade) a se perguntarem onde estão aquelas crianças, adolescentes e jovens da escola que não conseguem mais frequentálas? Quais são as políticas educacionais necessárias para produzir acesso e efetivar direitos das crianças e dos adolescentes? Certamente, cabe a todos nós observar e resistir às iniciativas governamentais que produzem mais violência e menos acesso à educação pública e de qualidade pelas populações mais vulnerabilizadas. 
NETO, R.C.; BERGER, W. M. D.; SOUZA, J. M. de; LATGÉ, P. K.; MACHADO, M. C. T.; ALVAREZ, M. M.

\section{POVERTY AND SOCIAL EXCLUSION IN VIOLATION RIGHTS OF CHILDREN AND ADOLESCENTS IN STREET SITUATION}

ABSTRACT: Children and adolescents in street situation, historically excluded subjects, human waste of surplus beings, those who do not fit the picture or school, away from educational policies. From a brief socio-historical perspective on the production of excluded children in Brazil, and the reality experienced in the extension project of a public university in the state of Rio de Janeiro, the purpose of this article was to discuss and understand how formal education, or its absence, marks the lives of these children and adolescents, taking as reference the life story of a young black woman whose first experience of social and institutional disruption was with the school. It affirms the urgency of less excluding and unequal social relations in order to enable the access and permanence of that population in school and its right to education.

KEYWORDS: People in street situation. Poverty. Social exclusion. Education.

\section{POBREZA Y EXCLUSIÓN SOCIAL EM LA VIOLACIÓN DE LOS DERECHOS DE LOS NIÑOS, NIÑAS Y ADOLESCENTES EM SITUACIÓN DE CALLE}

RESUMEN : Los niños y adolescentes en situación de calle, históricamente suprimidos, residuo de los seres humanos, las personas que no están en la foto y ni en la escuela, pasan liejo de las políticas educativas. A partir de un breve enfoque sócio-histórico sobre la producción de la infancia excluida en Brasil, y de la realidad vivida en el proyecto de extensión de la Universidad Pública del Estado de Río de Janeiro, con el propósito de garantizar la comunicación y la comprensión acerca de como una educación formal, o la ausencia de ella, marca la vida de esos niños y adolescentes, tomando como una referencia a la historia de vida de una joven negra, la experiencia de intercambio social e institucional para una escuela. Afirma una urgencia de relaciones sociales menos exclusivas y prácticas para el acceso y la permanencia de la población en la escuela y la dirección de la educación.

PALABRAS CLAVE: Personas em situación de calle. Exclusión social. Educación.

\section{REFERÊNCIAS}

ARAÚJ O, A. T. S.; SILVA, J . C. da; OLIVEIRA, F. M. da. Infância e adolescência e redução de danos/intervenção precoce: diretrizes para intervenção. Psicologia Argumento, Curitiba, n. 72, p.145-154, jan./fev./mar. 2013.

BAUMAN, Z. Vidas Desperdiçadas. Trad. Carlos Alberto Medeiros. Rio de J aneiro: Jorge Zahar Ed., 2005.

BONETI, L.W. Políticas públicas, educação e exclusão social. ljuí: UNIJUI, 1997. 
BRASIL. Ministério da Saúde. Política Nacional de Redução da Morbimortalidade por Acidentes e Violências: Portaria GM/MS n. 737 de 16/05/01 publicada no DOU n. 96 Seção 1e, de 18/05/01 Seção 1, Brasília, DF, 18 maio 2001.

BRASIL. Presidência da República. Secretaria de Governo. Índice de vulnerabilidade juvenil à violência 2017: desigualdade racial, municípios com mais de 100 mil habitantes / Secretaria de Governo da Presidência da República, Secretaria Nacional de Juventude e Fórum Brasileiro de Segurança Pública. São Paulo: Fórum Brasileiro de Segurança Pública, 2017.

CAMPOS, A. S. El delito de ser pobre: una gestión neoliberal de la marginalidade. Barcelona: Icaria \& Asaco, 2014.

CASTEL R. Da indigência à exclusão, a desfiliação - precariedade do trabalho e vulnerabilidade relacional. In: Lancetti A (org). Saúde e Loucura - 4. São Paulo: Hucitec; 1994.

0 advento de um individualismo negativo. Revista do Departamento de Psicologia - UFF, Niterói, n. 2 e 3, p. 4-11, 1996.

CASTRO, M. C.; OLIVEIRA, R. T. de. A incidência do racismo sobre a empregabilidade da juventude em Niterói e São Gonçalo (RJ). Niterói: Bem TV Educação e Comunicação, 2018.

DE PAULA, J. A. A extensão universitária: história, conceito e propostas. Interfaces Revista de Extensão. Belo Horizonte, n. 1, p. 5-23, jul./ago./set./out./nov. 2013.

FRANCISCO, A. C. B. L. M. Associação Protetora da Infância Desamparada: um olhar da família imperial para a criança desvalida. In: MENDONÇA, A. W. P. C. de; VASCONCELOS, M. C. C. (Orgs.). Histórias de Pesquisa na Educação. Rio de Janeiro: Quartet/Faperj, 2013, p. 255-288.

FREIRE, P. Extensão ou comunicação?Tradução de Rosisca Darcy de Oliveira. Rio de Janeiro: Paz e Terra, 1983. (O Mundo, Hoje, v. 24)

KOWARICK, L. A espoliação urbana. Rio de J aneiro: Paz e Terra, 1983.

LEITE,L.C. Meninos de rua: a infância excluída no Brasil. São Paulo: Atual, 2009.

MATTOS, R. A de. Os sentidos da Integralidade: algumas reflexões acerca de valores que merecem ser definidos. In: PINHEIRO R, MATTOS, R. A. de (Orgs.). Os sentidos da 
NETO, R.C.; BERGER, W. M. D.; SOUZA, J. M. de; LATGÉ, P. K.; MACHADO, M. C. T.; ALVAREZ, M. M.

Integralidade na atenção e no cuidado à saúde. Rio de J aneiro: IMS/UERJ/ABRASCO; 2006, p.43-88.

MOLINA, M. C. Política Educacional e Educação do Campo. Dicionário da Educação do Campo. São Paulo: Expressão Popular, 2012.

NASCIMENTO, M. L.; SCHEINVAR, S. Infância: discursos de proteção, práticas de exclusão. Estudos e Pesquisas em Psicologia, Rio de Janeiro, n. 2, p. 51-66, dez. 2005.

RIZZINI, I.; RIZZINI, I. A Institucionalização de Crianças no Brasil: percursos históricos e desafios do presente. Rio de Janeiro: Ed: PUC-RIO, 2004.

SCHUELER, A. F. M. de. Crianças e escolas na passagem do Império para a República. Revista Brasileira de História, São Paulo, n. 37, p. 59-84, set. 1999.

YANNOULAS, S.C.; ASSIS, S.G.; FERREIRA, K.M. Educação e pobreza: limiares de um campo em (re) definição. Revista Brasileira de Educação, n. 50, p. 329-351, mai./ago. 2012.

Ranulfo Cavalari Neto: Professor de Educação Física pela ESEFFEGO/Universidade Estadual de Goiás (UEG). Especialista em Saúde da Criança e do Adolescente, por meio do Programa de Residência Multiprofissional em Saúde da PUC-RS. Mestrando em Saúde Coletiva, linha de pesquisa Educação em/na Saúde, da Universidade Federal Fluminense (UFF). Atua no Projeto de Extensão Crianças e Adolescentes em Situação de Rua e Acolhimento institucional: construindo estratégias de territorialização afetiva.

E-mail: ranulfo-z3@hotmail.com

Sônia Maria Dantas Berger: Professora Adjunta do Instituto de Saúde Coletiva da Universidade Federal Fluminense (ISC/UFF). Pós-doutora pelo Programa de PósGraduação do Instituto de Estudos em Saúde Coletiva da Universidade Federal do Rio de Janeiro (IESC/UFRJ). Psicóloga formada pela Universidade Federal do Rio de Janeiro (UFRJ), com Doutorado e Mestrado em Saúde Pública pela Escola Nacional de Saúde Pública Sérgio Arouca da Fundação Oswaldo Cruz (ENSP-FIOCRUZ) e Especializações em Teorias e Práticas Ambulatoriais em Instituições Públicas (UFRJ e UFF).

E-mail: sdantasberger@smail.com

Joana Mansur de Souza: Graduanda de Psicologia pela Universidade Federal Fluminense. Estagiária da Equipe de Referência Infanto-Juvenil para Ações de Atenção ao Uso de Álcool e outras Drogas (ERIJAD), no município de Niterói. Bolsista do Projeto de Extensão Crianças e Adolescentes em Situação de Rua e Acolhimento institucional: construindo estratégias de territorialização afetiva.

E-mail: joanamansur@hotmail.com 
Paula Kwamme Latgé: Formação em Psicologia pela Universidade Federal Fluminense, mestrado em Saúde Coletiva pelo Programa de Pós-graduação em Saúde Coletiva - UFF, experiência de 16 anos na área da Gestão em Políticas Sociais, com destaque para Assistência Social e Saúde. Atua na Associação de Mídia Comunitária - BEM TV. Tem como projeto de pesquisa a institucionalidade do Sistema Único de Saúde e faz parte do Grupo de Estudos de Gestão e Ensino em Saúde- GEGES - ISC-PROPPI-UFF (GP (NPq).

E-mail: joanamansur@hotmail.com

Mônica Tereza Christa Machado: Possui graduação em Medicina Veterinária pela Universidade Federal Fluminense (1980), mestrado em Educação pela Universidade Federal do Rio de Janeiro (1996) e doutorado em Saúde Pública pela Escola Nacional de Saúde Pública/FIOCRUZ (2003). Atualmente é Professora Associada 4 Instituto de Saúde Coletiva, da Universidade Federal Fluminense, ministrando aulas em curso de graduação medicina e mestrado acadêmico (PPGSC). Atua principalmente nos seguintes temas: Avaliação da Atenção Básica, Saúde da Família, Saúde do Adolescente e crianças em situação de vulnerabilidade.

E-mail: monicatcmachado@gmail.com

Marlene Merino Alvarez: Doutorado em ciência da Nutriçao, participa do Projeto de Extensão Crianças e Adolescentes em Situação de Rua e Acolhimento institucional: construindo estratégias de territorialização afetiva, ambos desenvolvidos em articulação com as redes conveniadas de educação e saúde do Município de Niterói. Linha de pesquisa nas temáticas associadas a nutrição e vulnerabilidades, segurança alimentar, adolescente e obesidade.

E-mail: marlene.merino@smail.com

Este periódico utiliza a licença Creative Commons Attribution 3.0, para periódicos de acesso aberto (Open Archives Iniciative - OAI). 